\title{
Development of Prediction Methods Nutritional Status Athletes Using Fat-Free Mass Indicator
}

\author{
Mardiana $^{1}$, Yanesti Nuravianda Lestari ${ }^{2}$ \\ \{mardiana.ikm@mail.unnes.ac.id $\left.{ }^{1}\right\}$ \\ Universitas Negeri Semarang, Semarang, Indonesia ${ }^{1,2}$
}

\begin{abstract}
Many assessments of nutritional status using the body mass index (BMI) indicators that are carried out on athletes produce high BMI scores so that these athletes are considered to have over weight or obesity. Body weight is an indicator of body composition which includes the proportion of fat mass and fat-free mass including muscle mass, water, and bone. This study suggests cross-checking the results of anthropometric using the BMI indicator with other indicators, namely the percent body fat mass or the circumference ratio based on height. The cross-sectional design was used. The sample consisted of 118 student athletes who were under the Student Education and Training Center (PPLP). Measurements were made using body weight, height and fat-free mass. The results showed that there is a significant relationship between the percentage of body fat content and the BMI which is indicated by a $\mathrm{p}$ value $<0.05$.
\end{abstract}

Keywords: nutrition status, athletes, fat-free mas.

\section{Introduction}

Nutrition status is a condition of one's health that is described through the balance between intake and nutrients requirement of the body for growth and development of the body, physical activity, maintenance of health status and fulfillment of other biological needs [1]. Nutritional status can be known either directly or indirectly. The assessment of nutritional status directly one of them by using anthropometry index is Body Mass Index (BMI). For adult and elderly age group populations, BMI is still a valid indicator of nutritional status assessment, but this does not apply to athletes [2] The BMI indicator only calculates nutritional status through a proportion of body weight based on square height. Athletes who have a high BMI score cannot be inferred as having an overweight or even obese nutritional status. Many nutritional status assessments using BMI indicators performed on athletes produce a high BMI score so that it is considered that the athlete has more nutritional status as well as obesity. This is because weight is an indicator of body composition that includes a proportion of fat mass and fat-free mass including muscle mass, water, and bone that certainly cannot be known specifically only through weight measurement [3].

According to another research on 173 male and female athletes showed that as many as $72 \%$ of athletes have a BMI score but the fat period belongs to the normal category. This study suggests doing crosscheck anthropometry assessment results using BMI indicators with other indicators namely percent body fat mass or waist phallus ratio based on height [4]. Other studies conducted on 40 male athletes (20 runners and 20 handball athletes) and 30 non-athletes as controls showed results that there was no significant BMI difference between the athletes group 
(runners and handballs) and the control group (nonathletes). The body fat mass between the group of athletes and non athletes show a very significant difference, so BMI can not yet be used as an indicator describing nutritional status in athletes [5].

Measurement of nutritional status in athletes should pay attention to aspects of body composition both fat mass and fat-free mass. Therefore, the assessment of nutritional status in athletes will be more appropriate if done using indicators of body composition (fat mass and fat-free mass). Research on 57 male student athletes (football and handball) showed that REE (Resting Energy Expenditure) had an 84\% correlation with fat-free mass [6]. Similar research conducted on 93 female student athletes (track and field events, swimming, lacrosse, basketball, judo, beautiful gymnastics, rowing, cheerleaders, badminton, and weight lifting) also showed a strong correlation (82\%) between REE and fat-free mass [7]. The high correlation between REE and fat-free mass indicates that the higher the fat-free mass of an athlete, the higher the REE. Body fat mass that can be known by direct measurement (skinfold caliper or Bioelectrical Impedance Analysis or whole-body dual-energy X-ray absorptiometry scanner), fat-free mass can only be known through the estimation of several indicators of weight, height, and waist circumference which are then developed into an equation formula [8].

Therefore, researchers are interested in conducting research by means of trials and developing the equation formula in PPLP (Center for Student Education and Training) athletes in Central Java Province so that it can be a method to predict the nutritional status especially in athletes.

\section{Methods}

The type of research used in this study is crosssectional. A sample of 134 student athletes under the Center for Student Education and Training (PPLP) at Jatidiri Sport area complex. The subjects were selected using a purposive sampling. The inclusion criteria among subjects are not sick or have a history of cardiovascular disease, metabolic syndrome, immunity disorders and have not been used any medications or supplements that can effect muscle contraction. The subjects must fill informed consent form.

Anthropometric measurements using OMRON digital Personal Weight Scale Type HN289 ( $0,1 \mathrm{~cm}$ precision level) abd height measured using The GEA wireless Body Height Meter type $\mathrm{H}-721(0,1 \mathrm{~cm}$ precision level). The thickness of the subcutaneous fat was measured using the karadascan body composition monitor tyoe HBF-375. Measurements are performed using weight, height, and fat-free mass.

Characteristic data including age, height, body weight body fat percentage, fat free mass. BMI, waist circumference were analyzed descriptively and display by table. Bivariate analysis used the spearman Rank test to asses the predictor of measurement nutritional status.

\section{Results and Discussion}

This research was located in the GOR (Sports Arena) complex of Jatidiri Semarang, Central Java. Gor Jatidiri complex is a center of education and sports training for central Java student athletes located in Karangrejo, Gajahmungkur Subdistrict, Semarang City. The athletes who are built from sports include rowing, wushu, basketball, rock climbing, athletics, sepak takraw, fencing, volleyball, boxing, roller skates, taekwondo, karate, sand volleyball, football, 
wrestling, archery, pencak silat, weightlifting, swimming, athletics, and also disability athletics. The subjects in this study were 119 athletes from 16 sports including sepak takraw, weightlifting, swimming, fencing, basketball, rowing, volleyball, football, athletics, wrestling, wushu, karate, taekwondo, boxing, silat and judo.

The athletes who were the subjects in this study were only male athletes. Athletes who were the subject of the study conducted anthropometry measurements in the form of measurements of height, weight, body fat percentage, waist circumference, fat thickness (biceps, triceps, suprailiac, and subscapular), and fat-free mass. The body fat percentage is measured using two methods, namely with the BIA (Bio Impedance Analysis) tool that measures body fat percentage digitally and uses a manual method that is calculation based on fat thickness at some point. As for fat-free mass is also measured using BIA. However, BIA equations developed for specific athletes may also produce acceptable values and are still acceptable for use until more research is conducted. The use of a valid BIA equation/device should produce values similar to those of hydrostatic weighing and dual-energy X-ray absorptiometry. However, researchers and practitioners need to understand the individual variability associated with BIA estimations for both single assessments and repeated measurements [9]. In this study, anthropometry measurements are performed 3 times. During the study, there was 1 athlete who was dropped out because he was sick and could not follow the research, bringing the total sample to 118 male athletes. The complete characteristics of the study subjects are presented in Table 1 and Table 2 below.

Table 1. Characteristics of Research Subjects by Body Fat Mass

\begin{tabular}{|c|c|c|c|c|c|c|c|c|c|c|}
\hline \multirow{3}{*}{ Characteristics } & \multicolumn{10}{|c|}{ Charateristic of Body Fat Precentage Category } \\
\hline & \multicolumn{2}{|c|}{ Less } & \multicolumn{2}{|c|}{ Good } & \multicolumn{2}{|c|}{ Moderate } & \multicolumn{2}{|c|}{ Over } & \multicolumn{2}{|c|}{ Total } \\
\hline & $\mathrm{n}$ & $\%$ & $\mathrm{n}$ & $\%$ & $\mathrm{n}$ & $\%$ & $\mathrm{n}$ & $\%$ & $\mathrm{~N}$ & $\%$ \\
\hline BMI & & & & & & & & & & \\
\hline Wasting & 0 & 0 & 1 & 0,8 & 0 & 0 & 0 & 0 & 1 & 0,8 \\
\hline Underweight & 1 & 0,8 & 3 & 2,5 & 0 & 0 & 1 & 0,8 & 5 & 4,2 \\
\hline Normal & 0 & 0 & 62 & 52,5 & 31 & 26,3 & 5 & 4,2 & 98 & 83,1 \\
\hline Overweight & 0 & 0 & 6 & 5,1 & 2 & 1,7 & 6 & 5,1 & 14 & 11,9 \\
\hline
\end{tabular}

Relationship test using Spearman Rank Test, significant at level 0.01

Relationship test results show a significant value of $\mathrm{p}=0,003$, indicated by notation**

Based on table 1, it can be known that correlation the results using Spearman Rank Test show that there is a significant relationship between the percentage of body fat levels and Body Mass Index (BMI) indicated by a value of $\mathrm{p}<0,05$. Table 1 shows that BMI does not necessary describe body composition where there are subjects who have a wasting and normal BMI but measurement results show a slightly excessive percentage of body fat $(0,8 \%$ and $4,2 \%)$. In contrast, study subjects who had a good and sufficient percentage of body fat showed overweight BMI $(5,1 \%$ and $1,7 \%)$. This research appropriate to the other research on 173 male and female athletes showed that as many as $72 \%$ of athletes have a BMI score but the fat period belongs to normal category. Other studies conducted on 40 male athletes (20 runners and 20 handball athletes) and 30 non-athletes as controls showed results that there was no significant BMI difference between the athletes group (runners and handballs) and the control group (non athletes). The body fat mass between the group of athletes and non-athletes showed a very significant difference, so BMI can not yet be used as an indicator describing nutritional status in athletes [4]. 
Table 2. Characteristic of Subject

\begin{tabular}{lcccc}
\hline \multicolumn{1}{c}{ Charactristic $(\mathrm{n}=118)$} & Mean \pm SD & Min & Maks & p-value \\
\hline Age (years) & $16,18 \pm 1,129$ & 13,00 & 19,00 & $0,983^{\text {ns }}$ \\
Height $(\mathrm{cm})$ & $170,23 \pm 6,994$ & 154,00 & 186,6 & $0,0001^{* *}$ \\
Body weight $(\mathrm{kg})$ & $63,91 \pm 9,122$ & 47,15 & 93,85 & $0,0001^{* *}$ \\
Body Fat Percentage (\%) & $12,83 \pm 3,824$ & 5,40 & 24,40 & $0,005^{* *}$ \\
Fat Free Mass (kg) & $55,52 \pm 6,807$ & 39,39 & 75,04 & - \\
Body Mass Index /m $\left.{ }^{2}\right)$ & $22,00 \pm 22,386$ & 16,64 & 29,40 & $0,0001^{* *}$ \\
Waist circumference (cm) & $72,88 \pm 5,155$ & 61,75 & 87,80 & $0,0001^{* *}$ \\
Fat Thickness Under Skin & & & & \\
$\quad$ Bisep & $16,95 \pm 9,618$ & 4,00 & 38,00 & $0,012^{*}$ \\
$\quad$ Trisep & $20,43 \pm 10,280$ & 7,75 & 46,00 & $0,013^{*}$ \\
$\quad$ Suprailiac & $19,19 \pm 9,289$ & 5,00 & 47,00 & $0,007^{* *}$ \\
$\quad$ Subscapular & $18,49 \pm 9,559$ & 5,00 & 47,00 & $0,019^{*}$ \\
Body density (g/mL) & $1,03 \pm 0,011$ & 1,01 & 1,06 & $0,003^{* *}$ \\
\hline
\end{tabular}

Test relationships with fat-free mass bound variables using Pearson's R test Significant at the level of 0,05 , indicated by notation*

Significant at the level of 0,01 , indicated by notation** Insignificant indicated by notation ${ }^{\text {ns }}$

Based on table 2, it can be known that the student athletes who were the subjects of the study had characteristics of age, weight, height, body fat percentage, fat-free mass, waist circumference, thick under-skin fat, and fairly varied body density. It is known that the age of student athletes ranges from 13-19 years. The weight of the study subjects also showed varied measurement results ranging from $47.15-93.85 \mathrm{~kg}$. The height of the study subjects ranged from $154-186.6 \mathrm{~cm}$. The body fat percentage of the study subjects varied between $5.40-24.40$ $\%$. The fat-free mass of the study subjects also varied considerably between $39.39-75.04 \mathrm{~kg}$ of the subject's total body weight.

The results of the correlation test using Pearson's R stated that height, weight, body fat percentage, Body Mass Index, waist circumference, thick fat under the skin (biceps, triceps, suprailiac, and subscapular), and body density were significantly related to the fat>-free mass indicated by a $\mathrm{p}<0.05$ value, whereas the age variable was not significantly related to the fat $>$ free mass indicated by the $\mathrm{p}>0.05$ value.

In athletic populations, anthropometrics commonly includes measurement of height, weight, body circumferences (waist, hip, mid-thigh, calf, bicep), and subcutaneous ("skinfold") fat thickness. Assessment of body size and body composition can be a useful part of a general assessment but is particularly useful in athletes participating in weight class, gravitational, and esthetic sports where these factors may influence competition qualification, performance, or adjudication.10,11 Based on the results of correlation tests using Pearson's R it has been known 
that variables that are significantly related to fat-free mass are weight, height, body fat percentage, Body Mass Index, waist circumference, thick fat under the skin (biceps, triceps, suprailiac, and subscapular), and body density. Based on the results of correlation tests using Pearson's $\mathrm{R}$ it has been known that variables that are significantly related to fat-free mass are weight, height, body fat percentage, Body Mass Index, waist circumference, thick fat under the skin (biceps, triceps, suprailiac, and subscapular), and body density. The factors that will be studied greatly influence on the composition of fat-free mass only variable weight, height, waist circumference, and body fat percentage. These factors were then analyzed using multiple linear regression tests using the backward method [12].

The results of multiple linear regression analysis stated that height variables become insignificant if analyzed together with other variables indicated by the value $p>0.05(\mathrm{p}=0.414)$ so that height variables are excluded from predictors. After the height variable is removed, other variables namely weight, body fat percentage and waist circumference indicate a significant association with fat-free mass $(\mathrm{p}=0.0001 ; 0.0001 ; 0.0001$; and 0.002$)$. With the addition of a constant of 19,582 combined with the variables of body weight, body fat percentage, and waist circumference is a combination of determining variables that significantly affect the variable body fat mass. The equations formed from these variables are :

Fat-free mass $(\mathrm{kg})=19,582+0,858 * \mathrm{BW}-0,802 *$ Height $-0,120 *$ Waist Circumference

The above regression equation can be explained as follows :

Constant of 19,582 means that if the weight, height and waist circumference are 0 then the fat-free mass is the same as the constant.

Coefficient of regression of variable body weight of 0.858 atinya if other variables remain and the variable weight increases by $1 \mathrm{~kg}$ then the body fat mass will increase by $0.585 \mathrm{~kg}$.

Coefficient of regression of variable height of -0.802 means that if other variables remain and variable height increases by $1 \mathrm{~cm}$ then body fat mass will decrease by $0.802 \mathrm{~kg}$.

Coefficient of variable regression of waist circumference of -0.120 means that if other variables remain and variable circumference of the plate increases by $1 \mathrm{~cm}$ then the body fat mass will decrease by $0.120 \mathrm{~kg}$.

\section{Conclusion}

Based on the above results and discussions, conclusions that can be taken include height, weight, body fat percentage, Body Mass Index, waist circumference, thick fat under the skin (biceps, triceps, suprailiac, and subscapular), and body density is significantly related to fat-free mass. The regression equation formed is fat-free mass $(\mathrm{kg})=19,582+0.858 * \mathrm{BB}-0.802 * \mathrm{~TB}$ $-0.120 *$ Waist Circumference, but this equation still cannot be used as a predictive equation.

\section{References}

[1] William. 2007. Nutrition for Healt, Fitness and Sport. Eight Edition. Americas, New York

[2] Suyanto, S. Stanislaus. Pedoman Analisis Data dengan SPSS. Edisi ke-3. Graha Ilmu: Yogyakarta; 2009.

[3] Pontaga, L., Žīdens, J. Estimation of Body Mass Index in Team Sports Athletes. Lase Journa of Sport Science. 2011; 2(2); 33-44.

[4] Canda, A. Top Level Athletes with A Body Mass Index of 30 or Higher. Obesity or Good Muscle Development. Apunts Med Esport. 2017; 52(193): 29-36. 
[5] Gacéša, J.P., Barak, O., Jakovljevic, D.K., Klašnja, A., Galić V., Drapšin M., et.al. Body Mass Index and Body Fat Content in Elite Athletes. Exercise and Quality of Life. 2011; 3(2): 43-48.

[6] Oshima, S., Miyauchi, S., Kawano, H., Ishijima, T., Asaka, M., Taguchi, M., et.al. Fat Free Mass Can Be Utilized to Assess Resting Energy Expenditure for Male Athletes of Different Body Size. J. Nutr Sci Vitaminol. 2011; 57: 394- 400

[7] Taguchi, M., Ishikawa-Takata, K., Tatsuka, W., Katsuragi, C., Usui, C., et.al. Resting Energy Expenditure Can Be Assessed by Fat-Free Mass in Female Athletes Regardless of Body Size. J. Nutr Sci Vitaminol. 2011; 57: 22-29.

[8] Takai, Y., Nakatani, M., Aoki, T., Komori, D., Oyamada, K., Murata, K., et.al. Body Shape Indices are Prediktor for Estimating Fat-Free Mass in Male Athletes. PLoS ONE. 2018; 13(1); 1-12.

[9] The International Chair on Cardiometabolic Risk. WHR, Health Risk, and Intraabdominal Fat. [Online] Available at : http://wwww.myhealthywaist.org/evaluating-cmr/clinical-tools/waist-tohipratio/page/2/index.html\#EbookPage. [Accessed 4 Maret 2018].

[10] Ackland TR, Lohman TG, Sundgot-Borgen J, et al. Current status of body composition assessment in sport: review and position statement on behalf of the ad hoc research working group on body composition health and performance, under the auspices of the IOC medical commission. Sports Med. 2012; 42:227-49.

[11] Larson-Meyer, D. Enett. Nutrition Assessment for Athletes. Sport Med.2019; 18 (4): 105-108.

[12] Loenneke, Jeremy P et al. "The estimation of the fat free mass index in athletes." Asian journal of sports medicine vol. 3,3 (2012): 200-3. doi:10.5812/asjsm.34691 